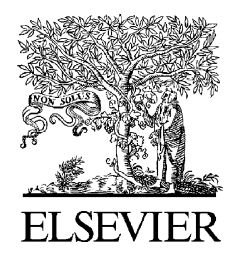

\title{
EDITORIAL
}

\section{Primum non nocere}

Primum non nocere (first do not harm) is the first sentence I heard when I started Medical School. It is also the very sentence that I pronounced when I obtained my medical degree. I think that this sentence, whether in Latin or in any other language, should be the primary goal for all physicians in the world. This is particularly true for non-lethal diseases for which safe and effective treatments exist.

"Hay fever" or "hay asthma" were terms proposed by Charles Blackley in the 1860's to describe pollen-induced rhinitis and th co-morbidities. In fact, "hay fever' 'ionisisading and should no longer "be lased becüuse "fever" "is 0 uncommon in at. al c rhiritis and the disa ase is not caused by "nay". It is surprisils tnat in 2005 such a name can still be used in a scientific publication [1].

Allergic rhinitis is a very common disease which affects quality of life and school/work productivity, but it is not a lethal disease. Very effective medications exist, albeit that some patients are not completely controlled with current medications [2]. At recommended doses these medications are well tolerated. Thus, only the safest medications can be recommended for this disease [3].

In this issue of the Primary Care Respiratory Journal, Østergaard et al. propose to use a single intramuscular injection of corticosteroid for the treatment of "hay fever" [1]. The authors state that "this review does not support concerns regarding possible tissue atrophy or other serious side effects... following a single intramuscular injection'. The authors have investigated the efficacy and safety of these drugs in the treatment of allergic rhinitis using a meta-analysis. The method used to retrieve adverse events is incorrect since the search strategy used the term "[AND] clinical trials"; clinical trials cannot be expected to predict all of the important adverse effects of medicines, and most adverse events are reported in post-marketing surveillance studies. No one would make conclusions on the safety of the oral contraceptive pill by looking at a few small clinical trials; rather, they would set up appropriate surveillance systems [4].

Only one post-marketings sinveilitance study has been reported [1 5]. STuer ty-six adverse events were reported ifir benmark after an estimated 330,000 patients were treated. It should be important olexarnine whether other studies are available.

It is surprising that some interesting papers reporting adverse events have not been referenced by Oostergaard et al. [1]. Reduction of cortisol levels lasting for up to three weeks were found after a single intramuscular corticosteroid injection $[5,6]$. Post-injection flare, facial flushing, and skin and fat atrophy are the most common side effects of injectable corticosteroids, whereas systemic complications are rare but do exist [7]. The most common adverse event, tissue atrophy, has even been reported in children [5,8-11]. Moreover, a more persistent and possibly greater effect on bones or eyes, lasting for weeks, cannot be excluded. Depot corticosteroid treatment for hay fever was found to cause avascular necrosis of both hips [12]. Finally, four fatalities related to intramuscular and intra-articular injections have been reported [13]. Although these systemic complications may be rare, they still exist, and patients with rhinitis should not be exposed to them when other safe and effective treatments exist.

If the season is exceptionally severe, or if the patient experiences prolonged symptoms as 
a result of multiple allergies, several injections may be necessary and this increases the risk of severe adverse events. However, serious adverse events can also be found with a single dose. For example, avascular necrosis of the hip is associated with corticosteroid therapy, but there is no direct relation with the total corticosteroid dosage [12].

As a physician, even though I have not treated 330,000 patients with allergic rhinitis, I can perfectly recall at least ten patients with severe adverse events following injectable corticosteroid treatment, most of them being tissue atrophy, but including two patients with very difficult-to-treat menstrual problems. I am therefore surprised that the authors of the paper, as primary care doctors seeing a large number of patients, have not noticed such adverse events.

I am concerned about the potential implications of this paper. Particularly in the USA and Canada, medico-legal issues have already arisen concerning the use of intramuscular corticosteroid treatment, and I believe that there is a potential liability risk for the authors if a physician were to quote this paper in his or her defence following a legal action by a patient.

In conclusion, I would like to ask one question. are any of the readers of this journal ready/tetake the rare but well-documentled risks associated with intramuscula cont cost teicid treatment for dilleigir rhinitis? I am Certainiy not willinoticlake such a risk, since I always apply the dictum Primum non nocere.

\section{Acknowledgements}

The author thanks Carlos Baena-Cagnani, Claus Bachert, Kai-Hakon Carsten, Wystke Fokkens, John Haughney, James Kemp, Richard J Lockey, David Price, Ono Van Schayck and De Yun Wang for helpful comments in the preparation of this editorial.

\section{References}

[1] Østergaard MS, Østrem A, Söderström M. Hay fever and a single intramuscular injection of corticosteroids: a systematic review. Prim Care Resp J 2005;14(3):124-30.

[2] Bousquet J, Van Cauwenberge P, Khaltaev N. Allergic rhinitis and its impact on asthma. J Allergy Clin Immunol 2001;108(5 Suppl):147-334.

[3] Bousquet J, Van-Cauwenberge P, Bachert C, Canonica G, Demoly P, Durham S, et al. Requirements for medications commonly used in the treatment of allergic rhinitis. Allergy 2003;58:192-7.

[4] Skegg DC. Evaluating the safety of medicines, with particular reference to contraception. Stat Med 2001;20(23):3557-69.

[5] Mygind N, Laursen LC, Dahl M. Systemic corticosteroid treatment for seasonal allergic rhinitis: a common but poorly documented therapy. Allergy 2000;55(1):11-5.

[6] Lazarevic MB, Skosey JL, Djordjevic-Denic G, Swedler WI, Zgradic I, Myones BL. Reduction of cortisol levels after single intra-articular and intramuscular steroid injection. Am J Med 1995;99(4):370-3.

[7] Cole BJ, Schumacher Jr HR. Injectable corticosteroids in modern practice. J Am Acad Orthop Surg 2005;13(1):37-46.

[8] Steffey JM. Letter: Subcutaneous atrophy following intramuscular administration of triamcinalone acetonide. Am J Dis Child 1973;126(4):561-2.

[9] Dyment PG. Local atrophy following triamcinolone injection. Pediatrics $1970 \cdot 46(1) \cdot 136-$

[10] Jacobs MB Loral sulor u aneous acrophy after corticosteroid injection. Pitgrad Med 1986;80(4):159-60.

(1) Clediry JD. Local atrolihy following steroid injection. Ann Pharmarath en $2(102 ; 6,4): 726$.

[12] Vosser Sil, Ewan PW. Lesson of the week: Depot corticosteroid treatment for hay fever causing avascular necrosis of both hips. BMJ 2001;322(7302):1589-91.

[13] Kortelainen ML, Sarkioja T. Fatal complications of intramuscular and intra-articular injections. Z Rechtsmed 1990;103(7):547-54.

Jean Bousquet

Clinique des Maladies Respiratoires

Hôpital Arnaud de Villeneuve, Centre Hospitalier

Universitaire, 191 avenue du Doyen G.Giraud 34295 Montpellier Cedex 5, France

* Tel.: +33 4673361 05; fax: +33 467042708 E-mail address: jean.bousquet@wanadoo.fr

13 March 2005

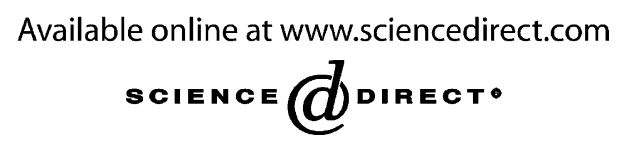

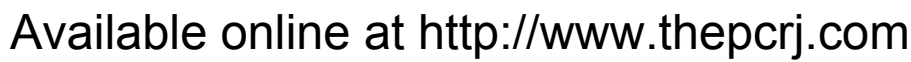

